\title{
The Effects of Public Spending Composition on Firm Productivity*
}

\author{
Richard Kneller $^{a}$ and Florian Misch ${ }^{b, \dagger}$ \\ ${ }^{a}$ School of Economics, University of Nottingham, Nottingham NG7 2RD, UK \\ ${ }^{b}$ Centre for European Economic Research, 68161 Mannheim, Germany
}

February 21, 2014

\begin{abstract}
This paper exploits the unique institutional features of South Africa to estimate the impact of provincial public spending on firm productivity. In contrast to existing microeconomic evidence, we explore the effects of fiscal expenditures and remove the effects of revenue raising policies. Our identification strategy is based on differences in the effects of public spending across firms within the same industry and province. We show that public spending composition affects productivity depending on the capital intensity of firms, with less capital intensive firms being particularly affected. These effects appear to be robust.
\end{abstract}

JEL code: D24, H32, H72

Keywords: Public Spending Composition; Productive Public Spending; Firm Productivity

\footnotetext{
${ }^{*}$ Generous financial support from Forfás is gratefully acknowledged. We thank the participants at a seminar in Dublin organized by Forfás for valuable comments. We are also grateful to Neil Rankin, the National Treasury, Republic of South Africa, and Kenneth Creamer who all faciliated the access and the use of the data used in this paper.

${ }^{\dagger}$ Corresponding author. E-mail address: misch@zew.de / Telephone: +49 (0) 6211235 394 / Fax: +49 (0)621 1235-223
} 


\section{Introduction}

It has long been understood within theories of economic growth and development that changes to fiscal policy, including changes in the composition of public spending, affect aggregate outcomes such as the rate of economic growth (Barro, 1990; Devarajan et al. 1996). Increasingly, cross-country empirical evidence has been found to support these model predictions. Adam and Bevan (2005), López and Miller (2007), and Hong and Ahmed (2009) all find for example, that greater productive expenditures, usually defined as including spending on transport, communication, education, and health, have significant positive growth effects (Gemmell et al., 2012, provide a recent survey).

The consistency of these findings suggests that they are robust. But because they are generated using macro data, they are still subject to criticism of Schwellnus and Arnold (2008) that they hide variation in their effects across firms and leave unclear the mechanism through which they are effective. Complementary evidence at the micro level is relatively uncommon and focused on a relatively narrow set of questions however; an outcome of limited availability of fiscal expenditure data measured at a sub-national level. As a consequence the literature has concentrated on the effects of changes to transport infrastructure, see for example Datta (2012), Shirley and Winston (2004) and Reinikka and Svensson (2002), and Arnold et al. (2008), or the investment climate more generally, see for example Bastos and Nasir (2004) and Dollar et al. (2005). ${ }^{1}$

In this paper we contribute to our understanding of the effects of fiscal policy by studying the effect of changes to the mix of public spending on the productivity of South African firms. For this task we exploit the richness of the fiscal data for South Africa, which include detailed types of health, education and transport expenditures at the province level. In this regard we build most closely on the work of Bekes and Murakozy (2005) and Gabe (2003), who find somewhat mixed evidence for the effects of fiscal policy on firms. Bekes and Murakozy (2005) find that in Hungary public investment by the central government had positive and significant effects on firm productiv-

\footnotetext{
${ }^{1}$ Our paper is also related to a large literature that dates however at least back to Mera (1973) which examines the effects of the stock of public capital (broadly defined) on private sector output at a more aggregate level; see Romp and de Haan (2007), Straub (2008) and Ligthart and Suárez (2011) for surveys of the literature. Several papers of this literature also exploit variation at the subnational level including Mera (1973), GarciaMilà and McGuire (1992), Baltagi and Pinnoi (1995) and Evans and Karras (1994). In addition, as Ligthart and Suárez (2011) note, many studies estimate a production function with public capital as in input. In this paper, we consider the flow of public spending as an explanatory variable and use firm-level data.
} 
ity, but that the effect of public investment by municipalities was negative. Gabe (2003) uses expenditure and revenue data to explain the growth of U.S. firms (measured as the change of employment), but finds no significant effect from either.

Alongside our interest in the effects of the mix of government spending we differ from the existing literature in our ability to disentangle this from revenue raising policies. At the provincial level in South Africa discretionary fiscal policy exists for the mix of expenditures. All broad based taxes are identical across provinces, and borrowing at the sub-national level is limited. ${ }^{2}$ As a result, the level of public spending can be viewed as exogenous to the individual province as it is dependent on grants from the central government. This is important in light of findings from macro growth regressions which show that the implicit assumptions about how fiscal changes are financed have a strong effect on the relationship with growth (Kneller et al., 1999).

To preview our results, we find that reallocating public resources can affect the productivity of some firms in the short to medium run (our data do not allow us to describe longer term impacts), where we use the capitallabor ratio to differentiate different types of firms. In this regard our findings support the argument of Schwellnus and Arnold (2008) that the effects of fiscal policy differ across firms, and, in addition, demonstrate that one of the transmission mechanisms through which aggregate growth changes occur is by changes to the productivity of firms. In our most parsimonious specifications we find that increasing expenditures on education, health, and transport as a share of total expenditures has a robust, positive and significant effect on the productivity of firms with the lowest capital-labor ratios (the bottom quartile). ${ }^{3}$ For those firms that use capital-to-labor with a greater intensity the effects are less frequently significant, while for those firms with the highest capital-labor ratios we find no effect.

We test the robustness of our findings to the inclusion of a wide set of province-industry and time dummies that might plausibly capture the effects of any omitted variables. For example, the productivity of firms and the choice of province-level fiscal expenditures might be affected by timeinvariant province-industry specific factors such as geography or climate. Or public expenditures might be targeted at particular industries in particular provinces because they have lower or higher productivity than elsewhere. Or it could occur that unobserved province-specific shocks affect the productivity of firms within a province and, through the automatic stabilizer mechanism,

\footnotetext{
${ }^{2}$ We describe the details of the system of fiscal decentralization in the Appendix.

${ }^{3}$ To correct for province-specific industry factors that cause the average capital-labor ratio to vary systematically across provinces and industries, the capital-labor ratio of the firm is measured relative to the mean in each individual industry and province.
} 
may generate a change to the mix of expenditures. We continue to find throughout this part of the paper evidence that firms with different capitallabor ratios are affected differently by changes to the expenditure mix. We cautiously describe this evidence as indicating rising (short-run) productivity of those firms with relatively low capital-labor ratios, and as consistent at least with a causal interpretation. The disadvantage of such an approach is that we cannot identify the overall magnitude of the effect of fiscal policy as any direct effects are captured by the province and industry dummies we include.

We also explore whether other firm characteristics matter for changes to the expenditure mix, by using information on the export status of the firm and their size. We find no evidence that these firm characteristics help to describe differences in the effects of fiscal policy across firms. The large number of categories of fiscal expenditure included within the South Africa data raise the possibility that there may be other changes to the expenditure mix that affect the productivity of firms other than those with relatively low capital-labor ratios. We explore this in detail and find limited evidence for such differences in our data, although the size of the effects do differ quite noticeably. The exception is for changes to education expenditure, funded by a decrease in health and transport spending, where we find no difference in the productivity effects across firms.

The paper is organized as follows. Section 2 presents the data and descriptive statistics. Section 3 develops the modelling framework. Section 4 discusses the results, and Section 5 presents several robustness checks of the results. Section 6 concludes.

\section{Data}

\subsection{Firm Level Data}

The information on firms that we use comes from the World Bank's Enterprise Surveys. These data are rich in detail on firm characteristics, and are designed to be representative of the population of (manufacturing) firms. They contain however, at least in comparison to other firm-level datasets, a relatively small number of observations and a limited panel dimension.

We use data from two rounds of the World Bank Enterprise Surveys in South Africa in 2002 and 2006, providing a total possible sample of 1,113 observations, covering both manufacturing and service sector firms. The survey contains questions that ask for information from earlier years, such that while most control variables are only available for 2002 and 2006, information 
on firm output and most inputs are available for four years (2000, 2001, 2002 and 2006). The panel is unbalanced with an average number of years per firm of approximately 1.95. We recognize that an implication of the limited time dimension of the data is that we are likely to identify productive effects from public spending that are relatively instantaneous and miss those that take longer to affect firm decisions. We are careful to recognize this point in the interpretation of our results for fiscal policy. Finally, we corrected the data for obvious keypunch errors, deleted observations with negative inputs or outputs and one observation with idiosyncratically high sales volatility.

The firms surveyed are located in four out of nine South African provinces and include Gauteng, Western Cape, Kwazulu-Natal and Eastern Cape (in descending order by the number of firms located in each province that are included in the surveys). Within each province considered, the majority of the firms are located in the biggest city (Johannesburg, Cape Town, Durban and Port Elizabeth). ${ }^{4}$ As most firms are located far away from other provinces, it seems unlikely that they benefit from spending from other provincial governments thereby minimizing problems of spillovers across provinces.

From the survey we use total firm sales as a proxy of firm output, the net book value of equipment and machines as a proxy of private capital, the number of employees and the cost of materials and intermediate goods. To account for the effects of inflation we deflate output using a sector-specific producer price index and the inputs using an economy-wide producer price index. We also collect from the Enterprise Surveys information on firm ownership, from which we create a dummy for foreign owned firms, whether they export or not and whether they have experienced losses due to crime. ${ }^{5}$ Tables 1 and 2 contain details about the firm-level variables and descriptive statistics.

\subsection{Public Spending Data}

Using information on the location of each firm it is possible to merge the World Bank Enterprise Survey data with provincial spending data provided by the South African Treasury and province-level control variables which were constructed from various official sources. This dataset includes public spending disaggregated at the sub-sectoral level and is available for all provinces for the fiscal years 2000/2001 through to 2005/2006 and province-level indicators of the quality of education, road infrastructure, levels of crime and

\footnotetext{
${ }^{4}$ In the Appendix, we describe the distribution of firms across industries and provinces in greater detail.

${ }^{5}$ A reliable variable for the age of the firm is not available and cannot be included. Since it would be time-invariant, firm fixed effects capture the effects of firm age.
} 
Table 1: Firm variables and provincial variables

\begin{tabular}{|c|c|c|}
\hline Variable & Description & Years \\
\hline sales $(y)$ & total sales per firm (in logs) & $2000,2001,2002,2006$ \\
\hline capital $(k)$ & $\begin{array}{l}\text { net book value of machinery, vehicles, } \\
\text { and equipment (in logs) }\end{array}$ & $2000,2001,2002,2006$ \\
\hline labor $(l)$ & total workers (in logs) & $2000,2001,2002,2006$ \\
\hline materials $(m)$ & $\begin{array}{l}\text { total cost of raw materials and intermediate } \\
\text { goods (in logs) }\end{array}$ & $2000,2001,2002,2006$ \\
\hline exporter & dummy ( 1 if firm sells goods in other countries) & 2002,2006 \\
\hline crime & $\begin{array}{l}\text { dummy ( } 1 \text { if firm suffers losses due to theft, } \\
\text { robbery, vandalism or arson) }\end{array}$ & 2002,2006 \\
\hline foreign & dummy ( 1 if foreign ownership $>10 \%$ ) & 2002,2006 \\
\hline large & dummy ( 1 if labor $>50)$ & 2002,2006 \\
\hline murder & murder rate in province (in logs) & $2001-2006$ \\
\hline road density & length of road / surface in province (in logs) & $2000-2006$ \\
\hline \multirow[t]{2}{*}{ grade } & percentage of learners who passed & $2000-2006$ \\
\hline & grade 12 in province (in logs) & \\
\hline city_GDP & GDP of the main city of province (in logs) & $2000-2006$ \\
\hline
\end{tabular}

Table 2: Firm variables - descriptive statistics

\begin{tabular}{lcccc}
\hline \hline Variable & Mean & Std. Dev. & Min. & Max. \\
\hline sales & 11.825 & 2.273 & 4.038 & 19.531 \\
capital & 10.058 & 2.087 & 2.641 & 16.832 \\
labor & 4.025 & 1.626 & 0 & 9.928 \\
materials & 11.054 & 2.471 & 1.948 & 19.442 \\
exporter & 0.092 & 0.289 & 0 & 1 \\
crime & 0.463 & 0.499 & 0 & 1 \\
foreign & 0.507 & 0.5 & 0 & 1 \\
large & 0.671 & 0.47 & 0 & 1 \\
\hline
\end{tabular}

The variable definitions can be found in Table 1 . 
the GDP of the main city (see Table 1$).{ }^{6}$ The public spending data contain information on both a broad set of functional expenditure categories, such as education and health, as well as different sub-categories of these functional expenditures. For example, as shown in Table 10 in the Appendix, within the education expenditure category, spending on ordinary school education and further education and training as well as adult basic training, early child development and subsidies for independent schools are separately catalogued. Again these are available for each province and fiscal year.

As described in the introduction, the objective of this paper is to explore whether changes to the mix of public spending can affect the productivity of at least some firms. Those effects will depend both on the particular category of spending that is changed and which other expenditure categories are assumed to decrease to compensate for this increase in order to leave total spending unchanged. The estimated coefficient will therefore reflect both the effects of the expenditure category that is increased and the effects of the expenditure categories that are decreased to compensate for the increase. It cannot be assumed for example, that the compensating categories have no effect on productivity. A coefficient of zero is consistent with both an interpretation that neither expenditure categories affect productivity and that the effects of both are of an equal size and therefore offsetting each other. That the expenditure data for South Africa are available at such a highly disaggregated level further stresses the need to consider this point carefully.

Our approach to this issue is to aggregate various expenditure categories to create a ratio variable in a way that we hope maximizes the possibility of finding an effect on productivity for some firms. We do so by including in the denominator total expenditure including those expenditure categories that when reduced, are less likely to affect productivity. In the numerator we generally include education, health and transport spending, but choose to remove various sub-categories within these areas (see Table 10 for more details), under a view that these are unlikely to impact the productivity of firms. When total expenditure is held constant, an increase in this ratio implies an increase in the expenditure categories included in the numerator offset by those expenditure categories only included in the denominator.

As these choices are, whilst informed by previous empirical evidence, subjective, we do not follow the previous literature in calling this the productive to unproductive expenditure ratio. Instead, we prefer a label that better

\footnotetext{
${ }^{6}$ Evidence suggests that the fiscal data for South Africa are of a high quality. Ajan and Aron (2007) and Quist et al. (2008) find that the level of transparency in South Africa's budget processes is high, while South Africa ranks among the top five developing countries in the Open Budget Survey on budget transparency and accountability.
} 
reflects the three main functional expenditure categories in the numerator, education, health and transport. We label this the EHT expenditure mix as shorthand and express it as a ratio to total public spending within a province in each time period. We describe non-EHT spending as 'other expenditure' in the text. This expenditure is assumed to offset an increase in EHT expenditure in the empirical specifications.

We also note that these three spending categories capture flows into the stock of human capital and transport infrastructure within a province. The effects of the stock of human capital and transport infrastructure are themselves captured by the province-time effects that are included in the regression. From our focus on flow expenditures we anticipate that we likely capture productivity effects that occur relatively quickly, within 1-2 years, and our results must be interpreted with that understanding in mind. We discuss the categorization of public spending in greater detail in the Appendix and consider the robustness of our findings to which specific items of government expenditure we consider in the numerator of our expenditure variable in Section 5.

Given that public spending may vary with business cycle fluctuations and any effects on productivity become apparent only after some lag, we follow the macroeconomic literature and average public spending over time (in our case across 2 years). Specifically, we combine the firm-level information for 2002 with the average of the fiscal data for the 2000/2001 and 2001/2002 fiscal years, and combine the average of fiscal data for the 2004/2005 and $2005 / 2006$ fiscal years with the firm data from 2006. The implication of this is that while our firm data are additionally available for 2000 and 2001, the public spending data are not. We trade this loss of information for reducing possible co-movement of the business cycle with firm-level productivity and the composition of government expenditure and against considering longer lags in the effects of public spending. Depending on the specification, we still use the 2000 and 2001 firm data for our estimation of firm production functions.

Table 3 provides descriptive statistics, and Figure 1 displays EHT spending and its subcomponents as shares of total provincial expenditure by province and year. Even with a relatively narrow definition of types of education, health and infrastructure spending, they account for 55 per cent of total province spending by the government. As the table makes clear, the variation in public spending categories comes primarily from variation between provinces rather than within provinces across time. The standard deviation between provinces is around 3 times that within provinces. Cross-time changes in the expenditure mix is evident though. The share of EHT spending increased in all provinces between 2002 and 2006 (where the 2002 and 
Table 3: EHT public spending (not in logs)

\begin{tabular}{lcccc}
\hline \hline $\begin{array}{c}\text { Variable } \\
\quad \text { as a share of total exp.) }\end{array}$ & Mean & $\begin{array}{c}\text { Std. Dev. } \\
\text { (overall) }\end{array}$ & $\begin{array}{c}\text { Std. Dev. } \\
\text { (between) }\end{array}$ & $\begin{array}{c}\text { Std. Dev. } \\
\text { (within) }\end{array}$ \\
EHT expenditure & 0.552 & 0.070 & 0.068 & .022 \\
of which education expenditure & 0.339 & 0.032 & 0.032 & .008 \\
of which health expenditure & 0.174 & 0.024 & 0.023 & .006 \\
of which transport and capital expenditure & 0.047 & 0.010 & 0.009 & .004 \\
\hline
\end{tabular}

2006 values are in fact both averages over two fiscal years as explained above) and the increases in Eastern Cape and KwaZulu-Natal were particularly large. The table also shows that a large part of EHT spending is on education, which are around twice as large as those for health and over 7 times those on transport and capital expenditure. Figure 1 implies that the shares of EHT spending increased in all four provinces over the period considered, but the relative increase varied and ranges from around 17 per cent in Western Cape to around 25 per cent in Eastern Cape.

Figure 1: EHT expenditure by province

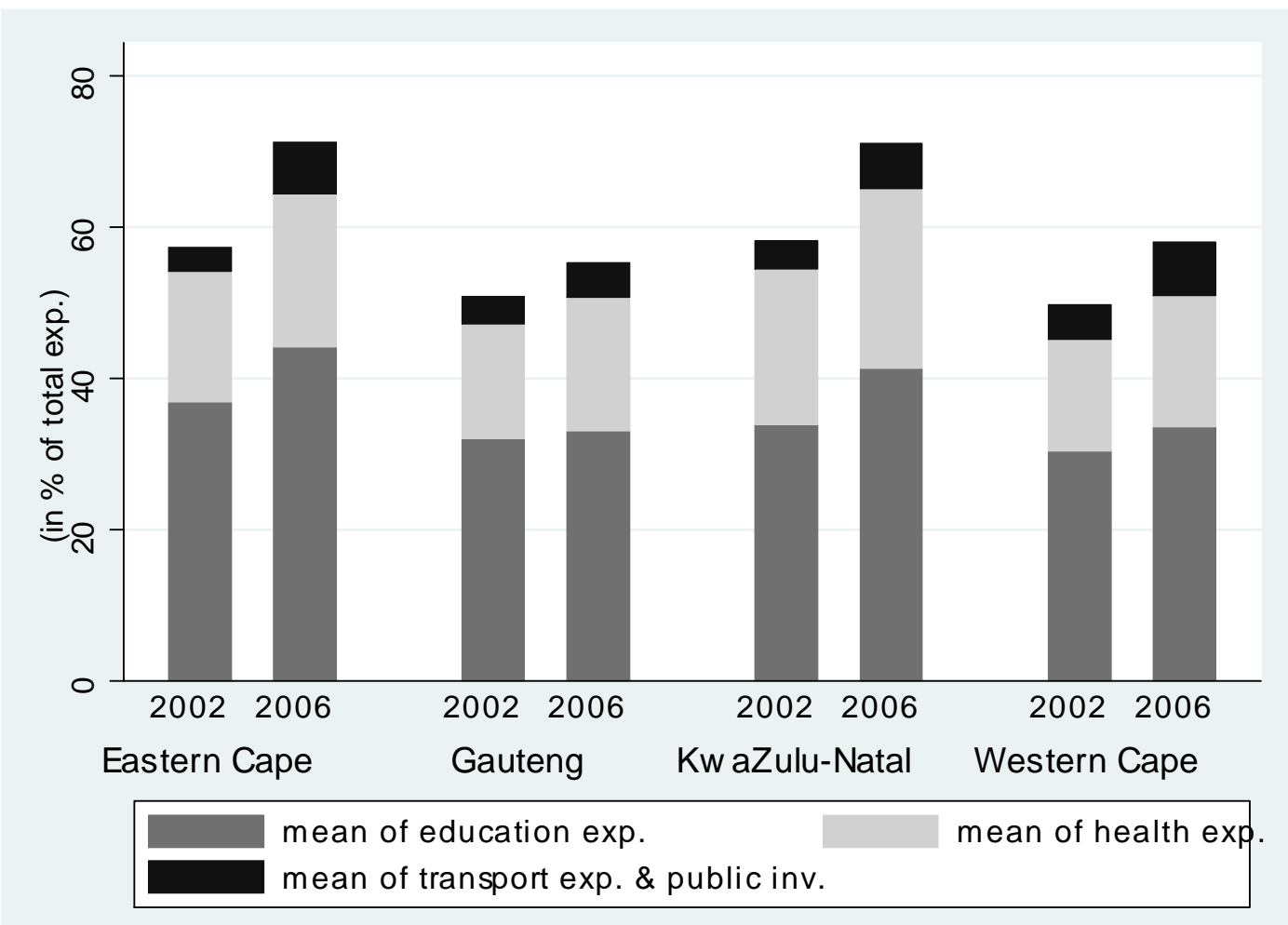




\section{Modelling Framework}

\subsection{Private Production}

As is typical in the literature we assume that output, $Y_{i t}$, of firm $i$ in year $t$, is produced using private capital $\left(K_{i t}\right)$, labor $\left(L_{i t}\right)$, and materials $\left(M_{i t}\right)$. Into this framework we incorporate a composite public input that represents the level of public services and public capital and that enhances firm productivity, $G_{p t}$, which varies across time and provinces, where $p$ denotes the province. As production technology, we use a fairly general type of CES production function originally proposed by David and van de Klundert (1965) which allows for the effects of $G_{p t}$ to be not Hicks-neutral:

$$
Y_{i t}=A\left[\left(\beta_{1} \epsilon_{K i} G_{p t}^{\left(\Psi_{K}+\Psi_{i}\right)} K_{i t}\right)^{v}+\left(\beta_{2} \epsilon_{L i} G_{p t}^{\left(\Psi_{L}+\Psi_{i}\right)} L_{i t}\right)^{v}+\left(\beta_{3} M_{i t}\right)^{v}\right]^{\frac{1}{v}}
$$

$G_{p t}$ can be written as

$$
G_{p t}=T_{p t} \phi_{p t} C_{p t}
$$

where $T_{p t}$ denotes total public spending in a given province in year $t, \phi_{p t}$ denotes the share of total public spending on $G_{p t}$ (i.e., that is devoted to productive categories, i.e., EHT categories as defined in the previous sections), and $C_{p t}$ represents other province-specific factors that relate to the efficiency of public spending. $\epsilon_{K i}, \epsilon_{L i}$ and $\Psi_{i}$ are firm-specific technology parameters contrary to $\beta_{1,2,3}, A, \Psi_{K, L}$ and $v$ which are also technology parameters but common to all firms. Including $G_{p t}$ in the production function captures the idea that private vehicles can be used more productively when the quality of the road network improves due for example, to lower maintenance requirements, or labor productivity is affected by health-related expenditures. ${ }^{7}$

\subsection{Hypotheses}

The inclusion of $G_{p t}$ in the production function implies that public spending affects firm-level productivity, which Barro (1990) refers to as the productive effects of public spending. Here, we are interested in the effects of changes in the composition of public spending which from (1) and (2) can be written as

$$
\frac{\partial Y_{i t}}{\partial \phi_{p t}}=Y_{i t}^{-1}\left[\begin{array}{c}
\left(\Psi_{K}+\Psi_{i}\right)\left(\beta_{1} \epsilon_{K i}\left(T_{p t} C_{p t}\right)^{\left(\Psi_{K}+\Psi_{i}\right)} K_{i t}\right)^{v} \phi_{p t}^{v\left(\Psi_{K}+\Psi_{i}\right)-1} \\
+\left(\Psi_{L}+\Psi_{i}\right)\left(\beta_{2} \epsilon_{L i}\left(T_{p t} C_{p t}\right)^{\left(\Psi_{K}+\Psi_{i}\right)} L_{i t}\right)^{v} \phi_{p t}^{v\left(\Psi_{L}+\Psi_{i}\right)-1}
\end{array}\right]
$$

\footnotetext{
${ }^{7}$ We recognize that there may be less direct mechanisms through which public spending affects firm productivity. For instance, total factor productivity may depend on capacity utilization, inventory levels and supplier relationships. Shirley and Winston (2004) develop a theoretical argument along these lines.
} 
From (3), we derive two key hypotheses with respect to the nature of the productive effects of public spending. First, increasing the share of public resources allocated to $G_{p t}, \phi_{p t}$, affects private sector output via its effect on productivity (hypothesis 1).

Second, these effects are heterogenous across firms as $\frac{\partial Y_{i t}}{\partial \phi_{p t}}$ is a function of $\epsilon_{K i}, \epsilon_{L i}$ and $\Psi_{i}$ among other factors (hypothesis 2). A priori, there is no reason to believe that these parameters are identical across all firms, and indeed, there is a host of reasons of why this assumption is likely to hold true. For example, the location of each firm determines access to public services and thereby the impact of $G_{p t}$ on firm productivity, or some firms may benefit from some types of expenditure more than others.

This simple framework does not make any predictions with respect to which type of firms under this categorization benefit more or less from EHT spending. However, it seems at least likely that $\epsilon_{K i}$ and $\epsilon_{L i}$, which are firmspecific determinants of the capital intensity, and $\Psi_{i}$ are correlated in specific ways for a given type of $G$. If $\epsilon_{K i} / \epsilon_{L i}$ dictates that a particular firm is relatively capital intensive and if $G$ primarily affects the productivity of labor, then we anticipate that $\Psi_{i}$ is relatively small. In such a case we would anticipate that firms that are relatively labor-intensive in their production technology are more likely to benefit from spending on health, education and public transport. Following this we initially use the capital-labor ratio of the firm to identify differences in the effects of policy. We detail how we measure the capital-labor ratio more fully in the next section of the paper.

\subsection{Econometric Specifications}

In the empirical work we approximate (1) using the following Translog function to test hypothesis 1 :

$$
\begin{aligned}
y_{i t}= & \alpha+\beta_{1} k_{i t}+\beta_{2} l_{i t}+\beta_{3} m_{i t}+\beta_{4} k_{i t}^{2}+\beta_{5} l_{i t}^{2}+\beta_{6} m_{i t}^{2}+\beta_{7} k_{i t} l_{i t} \\
& +\beta_{8} k_{i t} m_{i t}+\beta_{9} l_{i t} m_{i t}+\beta_{10} T_{p t}+\beta_{11} \phi_{p t}+\beta_{12} D_{j t}+\beta_{13} C_{i t}+\beta_{14} C_{p t}
\end{aligned}
$$

All variables are in logs (which is denoted by variables in lower case), $j$ denotes industry and $\phi_{p t}$ is the share of EHT spending in total expenditure. When testing for the effects of EHT spending, we hold total spending constant in the analysis by including $T_{p t}$. In this regard we follow a tradition established in the macro literature by Devarajan et al. (1996) in estimating the growth effects of changes in the public spending mix. We anticipate that the sign on the estimated coefficient for this variable can be positive or negative, depending on whether the negative effects of taxation outweigh the positive effects of total public spending (Barro, 1990). 
An important concern when testing the hypothesis whether the composition of public expenditures affects firm productivity (hypothesis 1), is that we are capturing the effect of some other omitted variable that is correlated with the expenditure mix and the error term from the regression. This form of endogeneity bias might be caused by time-varying changes to the preferences of regional governments towards private enterprise. For example, regions could adopt a strategy of openness towards international trade and FDI in order to encourage growth and investment and compensate the (perceived) negative effects of this by voters to the security of their employment by increased welfare payments (Rodrik, 1998). Alternatively, expenditures might be targeted at particular provinces because there is some province specific factor, such as its geography, that raises (or lowers) the productivity of all firms located there.

To control for observable firm and province variables that may affect the relationship between public spending and productivity, we include a series control variables denoted by $C_{i t}$ and $C_{p t}$, respectively. We include differences in the access to foreign technology between firms, which are measured by whether they are domestic or foreign owned, their export status variables and size. To control for the social environment in which firms operate, we add to the regression an indicator of whether the firm has been a victim of crime. We capture province-level characteristics that matter for productivity by including an indicator of the province-level crime rate (the murder rate), the level of public road infrastructure as the length of the road network in relation to the surface of each province (road density), the percentage of learners who passed grade 12 (grade), and to control for possible agglomeration and congestion effects, the GDP of the main city of the province where the firm is located (city_GDP). We also control for more difficult to observe factors using various dummy variables. In all of the regressions we include industry-year effects $\left(D_{j t}\right)$ to capture differences in productivity shocks across industries.

In later regressions in Section 4 we test the robustness of these findings to the inclusion of province-year effects $\left(D_{p t}\right)$ and province-industry effects $\left(D_{j p}\right)$. We use these to control for policy changes other than those to the expenditure mix that occur within a province during the sample period and time-invariant factors, such as geography or the general policy environment which changes only slowly over time, but which may affect the productivity of all firms within an industry and province. A consequence of the inclusion of the province-year effects within the equation is that we can no longer identify the direct effect of changes in the expenditure mix, captured by $\beta_{11}$ in equation (4), and the level of government spending, captured by $\beta_{10}$. By contrast, the relative effect, i.e., differences in the effect of spending on 
different firms can still be identified. We therefore turn to hypothesis 2 .

It has been discussed above that the relationship between changes to the expenditure mix and the productivity of different South African firms is likely to be dependent on the choice over which expenditure changes are examined. It is also likely to be dependent upon the way in which we identify those different firms. Our initial approach to this issue and to test hypothesis 2 is to use differences in the intensity with which firms use two main inputs, capital and labor, within the production function, the capital-labor ratio. That is not to deny the possibility that other characteristics may also be important, perhaps most obviously differences in firm size. Again, we test for the robustness of the results to this assumption.

To remove the effects of province or industry level factors that might affect the chosen mix between capital and labor we express this as a ratio to the annual province-industry mean. Specifically, we group firms according to their capital intensity relative to the annual province-industry mean, i.e., whether their relative capital intensity is low, lower medium, higher medium or high based on the quartiles of the distribution of capital intensities across all firms in all provinces and years. We use quartiles to capture the possibility of non-linearities in the effects of public spending. Equation (4) then becomes

$$
\begin{aligned}
y_{i t}= & \alpha+\beta_{1} k_{i t}+\beta_{2} l_{i t}+\beta_{3} m_{i t}+\beta_{4} k_{i t}^{2}+\beta_{5} l_{i t}^{2}+\beta_{6} m_{i t}^{2}+\beta_{7} k_{i t} l_{i t} \\
& +\beta_{8} k_{i t} m_{i t}+\beta_{9} l_{i t} m_{i t}+\beta_{10} G_{p t}+\beta_{11} \phi_{p t}+\beta_{12}[\text { low }] \phi_{p t}+\beta_{13}[\text { lmed }] \phi_{p t} \\
& +\beta_{14}[\text { hmed }] \phi_{p t}+\beta_{15}[\text { high }] \phi_{p t}+\beta_{16} D_{j t}+\beta_{17} C_{i t}
\end{aligned}
$$

and low, lmed, hmed and high represent dummy variables for the firms with relative capital intensities, $\frac{K_{i t}}{L_{i t}} / \frac{K_{p j t}}{L_{p j t}}$, below the $25 \mathrm{th}$, between the $25 \mathrm{th}$ and the 50th, between the 50th and 75th percentiles and above the 75th percentile, respectively. We then interact these dummies with the share of EHT spending in total expenditure $\phi_{p t}$. Given that capital and labor (in logs) are already included in various ways in the translog production function we do not include the capital intensity as an additional indicator in the regressions. While the relative effects of public spending can still be identified in equation (5), their interpretation is made problematic by the omission of the direct effect. We return to this issue and whether we can infer the direct effect of changes to public spending from our results below.

\section{Results}

In regression (1) in Table 5 we display the results from the estimation of equation (4) to test hypothesis 1 . In this regression we hold total expenditure 
constant and capture the effects of increasing EHT expenditure as a share of total expenditure on firm sales.

Starting with the control variables we find that the production function performs sensibly and the estimated elasticities (calculated at the means of the other right-hand side variables) are within the expected range. The elasticity with respect to physical capital and labor in regression (1) are 0.075 and 0.229 respectively and there are mildly increasing returns across all of the private inputs for the firms in our sample. Of the firm and province-level variables only the crime variable and the city_GDP variables are statistically significant at conventional levels, with the latter having a surprising negative effect on firm productivity. This may indicate that there are congestion effects in large cities which lower productivity.

Turning next to the fiscal variables, the estimated coefficient for total expenditure is negative and statistically significant. Using the Barro (1990) model to interpret this result would imply that the level of government expenditure is beyond the optimal point in South Africa, such that the negative effects of taxation on growth outweigh any positive effects that expenditures might have. For the main variable of interest, the share of EHT spending, we find that this has a positive relationship with firm sales (with significance at the $10 \%$ level), suggesting that changes to the expenditure mix is associated with rising productivity on average.

Regression 2 in Table 5 refers to our baseline estimation of hypothesis (2) and captures alongside the effect of changes to total government spending the possibility that they differ across firms with different capital-labor ratios. Note that the capital-labor ratio of the firm is measured relative to the mean in each individual industry, province and time period. In all regressions we continue to control for shocks to industries using a full set of industry-time dummies and use province-industry clustered standard errors to control for intra-class correlation. $^{8}$

For the effects of EHT expenditure, we find evidence of an interesting difference in its effect across firms. The coefficients for this variable can be interpreted as the effect on firm-level productivity of an increase in the EHT share compensated by a pro-rata decrease in other types of public spending, leaving total province expenditures constant. The results indicate that such a change to fiscal policy would increase productivity for firms with all but the highest capital-labor ratios with significance at the $10 \%$ level, for whom we find no effect at least over the short-run. As already noted this could

\footnotetext{
${ }^{8}$ The number of provinces is too small to cluster at the provincial level only. To further control for intra-class correlation, we use the wild cluster bootstrap indicator as proposed by Cameron et al. (2008) which we discuss further below.
} 
imply either that there is no effect from changes to the expenditure mix for these firms, or that the compensating items have an effect that offsets the effect of increased EHT spending for these firms.

In regression (3) we account for the effect of time-varying province as well as time-invariant province-industry characteristics that have been omitted from regression (2). The former might include province-specific components of the business cycle and policy variables not directly related to fiscal policy, while the latter allow for province characteristics such as geography, that might affect the productivity of firms within an industry compared to those in the same industry and a different province.

The province-time dummies are of course perfectly collinear with the government expenditure variables, such that the total expenditure variable must be omitted. This also necessitates a change in the way that we include these dummies, and we omit the high capital-labor ratio group, such that we now test for differences in the effects of fiscal policy relative to the reference category.

The results from regression (3) now indicate that half of South-African firms are affected by changes to the expenditure mix (with significance at the $5 \%$ and $10 \%$ level, respectively). As in regression (2) we find that the productivity of those firms with the low and lower medium capital labor ratios are affected by changes to the expenditure mix. A strict interpretation of the results from this regression would be that firms which use relatively less (low and lower medium) capital to labor in production are affected differently compared to firms with other capital-labor ratios from increasing the share of spending on EHT within total fiscal expenditures over the short-run. If, as implied by the results from regression (2), the productivity of those firms with the highest capital-labor ratios is unaffected by these changes to the expenditure mix, then this interpretation might be further strengthened to say that the productivity of low capital-labor ratio firms is increased. We continue to make this assumption throughout the rest of the paper.

To evaluate the magnitude of these effects further, from Table 3 we calculate that the average increase in the share of EHT expenditures within South African provinces over time (relative to the mean) was equal to 4 per cent (the mean is 0.552 and the within province standard deviation 0.022). Multiplying this number with the coefficient estimate suggests that for firms with a low capital-labor ratio productivity would change by 0.88 per cent compared to high capital-labor ratio firms. The coefficient estimate of the share of EHT spending is relatively large (for instance compared to the coefficient on private capital). However, in practice, the productivity outcomes are not that large when the actual variation in the fiscal data is considered.

As discussed above, a natural extension of the above analysis is to ex- 
plore whether there are alternative changes to the expenditure mix that would stimulate the productivity of high capital-labor firms. We consider this question in more detail in Table 7, using the remaining regressions in Section 5 to explore the robustness of the initial findings.

As already highlighted an important concern is whether our results capture the effect of unobservable province-industry time-varying factors that affect both the productivity of firms within a province and the mix of fiscal expenditures. In the absence of suitable variables to instrument for the expenditure mix within a province, we continue with the practice started in regression (3) of adding further control variables. This allows us to at least judge how important omitted variables are likely to be for the results that we find. In regression (3) we included a full set of province-year and provinceindustry dummies. In regression (4) we develop this further and control for the possibility that there are shocks that occur at the province-industry-time level that affect productivity and the expenditure variables. The effect of the changes to the expenditure mix are therefore identified in this regression from differences in the effect of policy across firms within the same province, industry and year.

Despite the demanding nature of this identification strategy we find that our results are left unchanged. We continue to find evidence that those firms that have a low or a medium-low ratio of capital to labor relative to other firms in their industry in that province are affected by shifting the expenditure mix compared to high $\mathrm{K} / \mathrm{L}$ firms. We also find that the magnitude of these effects are very similar to those from regression (3), suggesting that omitted province-industry-time effects were not an important explanation for the results in the earlier regressions.

\section{Robustness of the Results}

\subsection{Endogeneity of Private Inputs and the Clustering of the Standard Errors}

Given the lack of a counterpart in the empirical literature, we feel that it is important to establish the robustness of our findings to a number of different methodologies. Our first robustness check addresses potential concerns about the endogeneity of the coefficients on private inputs including private capital. It may be argued that the parameter values on the private inputs in the production function are poorly identified as our regressions do not exploit all of the firm-level data available to us - so far they use data for 2002 and 2006 only. 
In order to exploit the full four years of firm data, we proceed by estimating (5) in two steps. In the first step we estimate equation (5) including all four years of available data. In this step, we include firm fixed effects and province-year effects for 2002 and 2006, to avoid any bias caused by omitting the remaining variables (including the fiscal variables) from this regression. ${ }^{9}$ In the second step we impose the coefficients on the private input variables estimated in step 1 and then re-estimate the model including the firm and fiscal variables that were omitted from the first stage. We hope from this exercise to improve the precision with which we estimate the coefficients on the input variables.

In regression (5) of Table 5, we report the results from the two-stage estimation where the first stage is estimated using firm fixed effects. Again the results are robust to this point. ${ }^{10}$ In the two-stage estimation results we continue to find that the coefficients on the fiscal variables are statistically significant and that the estimated elasticities are largely unchanged. Changing the mix of province-level expenditures towards EHT spending categories whilst holding the total budget constant, is associated with changes in firm-level output for firms with a low capital intensity. ${ }^{11}$

Another concern relates to the clustering of the standard errors. In regression (1) Table 6 we therefore use the wild cluster bootstrap estimator proposed by Cameron et al. (2008) to further control for intra-class correlation at the province and industry level. In this specification, we are only able to include province-year effects. The coefficient on the share of EHT expenditure for firms with a low capital intensity remains significant and robust, although their magnitude decreases.

\subsection{Categorization of Firms and Unobserved Firm-Level Characteristics}

Thus far we have used differences in the relative factor intensity of capital and labor of firms to identify the effects of changes to the public expenditure mix on productivity performance. The decision to express these capital-labor ratios relative to the mean value in each industry, province and year, along with the province-time and province-industry dummies that we include, ensures that our results cannot be explained by differences in the characteristics

\footnotetext{
${ }^{9}$ Given that the location of firms in 2000 and 2001 is unknown, we cannot include province-year effects in these regressions. As a robustness check, we also ran regressions with no province-year effects and with province-year effects for all years.

${ }^{10}$ The standard errors of the output elasticities with respect to the private inputs come from the first stage.

${ }^{11}$ Our results are also robust to the use of the Levinsohn-Petrin (2003) estimator.
} 
of particular industries, or because province-specific differences in relative input prices lead to different factor intensities across provinces. Along similar lines, our results cannot reflect the decision by an entrepreneur to open a firm producing a particular type of product in a particular province because the expenditure mix in that province favors a production technology of that type. Such effects will instead be reflected in the mean value of the capital-labor ratio.

The possibility that other firm characteristics might explain our results, or may also be important, remains however. For example, if larger firms tend to be on average more capital intensive than smaller firms, then it might be the relative size of firm, rather than capital-labor intensity, that is important. Alternatively, it is now well established in the international economics literature that exporters are larger and more productive than firms that serve the domestic market only and they may therefore respond to changes in the expenditure mix differently.

In specification (2) in Table 6 we report the results when including interactions between the export status of the firms and the share of EHT expenditure alongside the versions based on the capital-labor ratio. The results show that the export status has no significant effect for the relationship with the change in the spending mix that we examine. ${ }^{12}$

In regressions (3) and (4) in Table 6 we explore whether the size of the firm affects the relationship with changes to the mix of public spending, which we measure by the amount of labor, relative to the province-industry mean, and the size of the capital stock, measured relative to the province-industry mean (we retain the labelling of low, lmed and hmed).

We do not find that the share of EHT expenditures matters for any of these types of firms. Firms that are small, or medium sized, when measured by either the amount of labor or capital they possess, are not significantly affected by an increase in EHT spending compensated by a decrease in other types of spending. We conclude from this exercise that the capital-labor ratio successfully captures which firms are affected by changes to fiscal policy that we examine.

As an additional exercise, we test whether our results are driven by the particular way in which we group firms based on their relative capital-labor intensity. In specification (5), instead of using quartiles, we use quintiles of the distribution of capital-labor across firms. In specification (5) we continue to find that the effects of the share of EHT spending are significant for the bottom groups. ${ }^{13}$

\footnotetext{
${ }^{12}$ We do not rule out the possibility that this type of interaction helps to identify an effect for a change in spending we have not considered.

${ }^{13}$ Our results also remain robust to using terciles of the distribution of the relative
} 
Table 4: Attrition rates

\begin{tabular}{lc}
\hline \hline Capital & \% of firms in 2002 \\
intensity & that are still in sample 2006 \\
\hline low & $24.6 \%$ \\
lower medium & $34.8 \%$ \\
upper medium & $28.9 \%$ \\
high & $30.2 \%$ \\
\hline
\end{tabular}

Another concern is that we insufficiently control for unobserved firm-level characteristics. While we control for firm fixed effects in the first step of the two-stage specifications, in specification (1) of Table 7, we also add firm fixed effects. Even though we only have two years of data which is the reason why we normally do not use firm fixed effects at this stage in the remaining specifications, our results remain robust.

Finally, there may be a concern about the classification of firms as our panel is unbalanced. If capital intensity is correlated with productivity, then firm exit rates can assumed to be highest in the low capital-intensity group and lowest in the high capital-intensity group. This would imply that the panel is not unbalanced for idiosyncratic reasons which may bias the results. In our sample, we define attrition as firms that are included in the sample in the 2002 wave but not in the 2006 wave. ${ }^{14}$ Attrition rates do indeed differ between the groups, and they are highest in the low capital-labor group. However, there does not appear to be a systematic pattern, as they are by far lowest in the medium capital intensity group. The difference in attrition rates between the low-capital intensity group and the omitted capital intensity group (which may have the highest productivity according to this reasoning) is about six percentage points and therefore relatively small. Table 4 provides details. ${ }^{15}$

capital intensities (not shown).

${ }^{14} \mathrm{By}$ construction of the firm-level data, there is no attrition prior to 2002 as the panel dimension for 2000 and 2001 is constructed from the 2002 questionnaire only. In addition, we do not observe attrition after 2006.

${ }^{15}$ When we only include firms with observations in 2002 and 2006 in specification (1) of Table 7, the coefficients remain robust which is not surprising. However, this further suggests that differences in attrition rates do not affect our results. 


\subsection{Definition of Public Expenditure and Exogeneity of its Composition}

The richness of the public spending data for South Africa throws up an interesting question, namely of whether there are alternative changes to the mix of public spending that affect the productivity of firms, and whether or not those firms with low and medium-low capital intensity are affected by these changes. As explained above, given our definition of the expenditure mix this will depend on the choice of fiscal expenditures that are assumed to increase as well as which ones are assumed to decrease to compensate for this. We use this section of the paper to explore issues relating to our categorization of public spending.

We begin with some discussion of the denominator of the EHT variable, which includes the remaining province-level public spending. Even though we take averages of public spending over two years, it is conceivable that the denominator of the spending share variable co-moves with the business cycle because it includes transfers or other expenditures that exhibit pro-cyclical behavior. While correlations between regional growth rates and the public spending shares we construct indicates that this is unlikely (the correlation coefficient between the annual share of EHT spending and provincial growth is below 0.25 and statistically not different from zero), specification (2) of Table 7 considers this more formally.

In regression (2) of Table 7 we express EHT expenditure as a share of total expenditure on education, health and transport sectors (i.e., the denominator also includes for instance administrative spending within these categories, but no spending outside these categories). The results from this regression suggest that reallocating resources within total education, health and transport spending also affects the productivity of firms according to their capital-labor ratio. Again we find no productivity response for firms with a capital-labor ratio above this.

In specification (3), we develop this idea further and exclude both spending on emergency care and on public works from the denominator. A possibility exists that these expenditure categories have a different sensitivity to cyclical fluctuations compared to the remaining expenditure items. For political reasons, emergency care spending may be safeguarded from cuts and remain fairly stable over the cycle, while in contrast, public works are subject to long planning and execution cycles. Specification (3) now suggests that only the productivity of those firms with the lowest capital-labor ratios would be affected by increasing this spending ratio.

Also of interest are whether our results are driven by the particular way in which we define EHT expenditures. Thus far we have included sub-categories 
of education, health and public infrastructure and transportation that may be expected to be productive over the short run. When we include all subcategories of health, education as well as public infrastructure and transportation, where this now includes expenditures on administration, in specification (4) of Table 7, the coefficient of the share of EHT expenditure is again statistically significant for firms with low and medium-low capital-labor ratios.

In specification (5), we take the alternative approach and are more selective in the subcategories of education, health as well as public infrastructure and transportation spending we include. In this regression we include in the numerator expenditure on early childhood development, district health services and spending on public transportation only. The coefficients for medium-low and low $\mathrm{K} / \mathrm{L}$ are much reduced in size, but remain positive and significant in these regressions. It is also noticeable that the estimated coefficients are much smaller than those found up until this point, suggesting that while significant the relative productivity changes they cause across firms are comparatively small compared to other changes to the expenditure mix.

As a final exercise we include education, health and transport as separate categories and express them as a ratio to total EHT expenditure. These are reported in regressions (1), (2) and (3) in Table 8. Interestingly we now find a significant productivity effect only for health and transport spending for low and medium-low capital labor ratio firms. As already noted, this does not necessarily imply there are no productivity effects from changes to education expenditure as they may be offset by the other compensating changes that occur in order to leave total expenditure constant. It does at least indicate that low $\mathrm{K} / \mathrm{L}$ firms are not always affected by changes to the expenditure mix in a way that is different from firms with higher $\mathrm{K} / \mathrm{L}$ ratios.

\section{Conclusions}

This paper examines whether changes in the composition of public spending affects firm productivity and whether these effects depend on firm characteristics. We show that an increase in education, health and transport spending compensated by a pro-rata decrease in other types of expenditure so as to leave total expenditure constant matters for firm productivity, and that there is evidence that its effects vary across firms depending on their capital intensities. We also show that those effects vary with the exact change to the expenditure mix that occurs, that differences are not found across all firms for all changes to the expenditure mix and that there are differences in the size of any effects. We find however, that firm characteristics other than the capital-labor ratio play no important role. We also find indicative evidence 
that low K/L firms benefit from changes to the expenditure mix as their productivity rises in contrast to more capital intensive firms.

We conclude from the evidence we present that governments are able to affect firm productivity by reallocating public spending. Given that productivity at the firm level is likely to be fundamental for long-run aggregate economic growth, changes to the expenditure mix may be less expensive than raising total public spending and therefore raising additional revenues. This is of current relevance given the large budget deficits due to the recent economic crisis in many countries. Second, if governments attempt to raise firm productivity via the reallocation of public resources, our results indicate that it is important that they take into account the characteristics of firms. While this issue needs to be further explored in future research, our results indicate that these effects depend on the technology of firms that in turn drive their capital intensities.

We leave several possible extensions for future work. The robustness of the results could be further tested through the use of additional estimators and empirical methods. Our identification strategy addresses endogeneity in a manner that is similar to many other papers using macro and micro level data, but concerns over the direction of causation therefore still remain. There are also other aspects of the dataset that could be exploited further. For instance, it would be possible to compare the effects of aggregate EHT spending when offset by different elements of the government budget, and it would be possible to explore the role of additional firm characteristics for the effects of public spending.

One constraint of our data is certainly the availability of firm information across fairly short time periods so that we are only able to capture any effects on productivity that occur over the short run. This implies that we are unable to rule out that these short-run productivity gains come at the expense of long-run productivity gains. 


\begin{tabular}{|c|c|c|c|c|c|}
\hline VARIABLES & $\begin{array}{c}(1) \\
\text { sales }\end{array}$ & $\begin{array}{c}(2) \\
\text { sales }\end{array}$ & $\begin{array}{c}(3) \\
\text { sales }\end{array}$ & $\begin{array}{c}(4) \\
\text { sales }\end{array}$ & $\begin{array}{c}(5) \\
\text { sales }\end{array}$ \\
\hline capital & $\begin{array}{c}0.0754^{* * *} \\
(0.0117)\end{array}$ & $\begin{array}{c}0.0563^{* * *} \\
(0.0167)\end{array}$ & $\begin{array}{c}0.0481^{* * *} \\
(0.0191)\end{array}$ & $\begin{array}{c}0.0420^{* *} \\
(0.0338)\end{array}$ & $\begin{array}{l}0.0311 \\
(0.0421)\end{array}$ \\
\hline labour & $\begin{array}{c}0.229^{* * *} \\
(0.0245)\end{array}$ & $\begin{array}{c}0.245^{* * *} \\
(0.0282)\end{array}$ & $\begin{array}{c}0.258^{* * *} \\
(0.0300)\end{array}$ & $\begin{array}{c}0.264^{* * *} \\
(0.0202)\end{array}$ & $\begin{array}{c}0.228^{* * *} \\
(0.0626)\end{array}$ \\
\hline materials & $\begin{array}{c}0.721^{* * *} \\
(0.0186)\end{array}$ & $\begin{array}{c}0.721^{* * *} \\
(0.0183)\end{array}$ & $\begin{array}{c}0.719^{* * *} \\
(0.0180)\end{array}$ & $\begin{array}{c}0.719^{* * *} \\
(0.0202)\end{array}$ & $\begin{array}{c}0.745^{* * *} \\
(0.0241)\end{array}$ \\
\hline foreign & $\begin{array}{c}0.0392 \\
(0.0268)\end{array}$ & $\begin{array}{l}0.0393 \\
(0.0268)\end{array}$ & $\begin{array}{l}0.0305 \\
(0.0268)\end{array}$ & $\begin{array}{l}0.0264 \\
(0.0278)\end{array}$ & $\begin{array}{l}0.0347 \\
(0.0279)\end{array}$ \\
\hline large & $\begin{array}{l}0.0179 \\
(0.0356)\end{array}$ & $\begin{array}{l}0.0235 \\
(0.0367)\end{array}$ & $\begin{array}{l}0.0310 \\
(0.0377)\end{array}$ & $\begin{array}{l}0.0356 \\
(0.0396)\end{array}$ & $\begin{array}{c}0.0842^{* * *} \\
(0.0306)\end{array}$ \\
\hline exporter & $\begin{array}{c}0.0259 \\
(0.0249)\end{array}$ & $\begin{array}{l}0.0266 \\
(0.0249)\end{array}$ & $\begin{array}{l}0.0198 \\
(0.0242)\end{array}$ & $\begin{array}{l}0.0197 \\
(0.0248)\end{array}$ & $\begin{array}{l}0.0253 \\
(0.0280)\end{array}$ \\
\hline crime & $\begin{array}{c}-0.0268^{*} \\
(0.0156)\end{array}$ & $\begin{array}{l}-0.0244 \\
(0.0156)\end{array}$ & $\begin{array}{l}-0.0200 \\
(0.0154)\end{array}$ & $\begin{array}{l}-0.0151 \\
(0.0161)\end{array}$ & $\begin{array}{c}-0.0273^{*} \\
(0.0153)\end{array}$ \\
\hline grade & $\begin{array}{l}0.470 \\
(0.493)\end{array}$ & $\begin{array}{c}0.548 \\
(0.470)\end{array}$ & & & \\
\hline city_GDP & $\begin{array}{c}-0.346^{* * *} \\
(0.123)\end{array}$ & $\begin{array}{c}-0.340^{* * *} \\
(0.127)\end{array}$ & & & \\
\hline murder & $\begin{array}{l}-0.191 \\
(0.216)\end{array}$ & $\begin{array}{l}-0.240 \\
(0.209)\end{array}$ & & & \\
\hline road density & $\begin{array}{c}0.000182 \\
(0.00706)\end{array}$ & $\begin{array}{c}-0.00129 \\
(0.00665)\end{array}$ & & & \\
\hline total exp. & $\begin{array}{c}-0.652^{* * *} \\
(0.227)\end{array}$ & $\begin{array}{c}-0.622^{* *} \\
(0.236)\end{array}$ & & & \\
\hline EHT exp. low $([\mathrm{Kit} / \mathrm{Lit}] /[\mathrm{Kjpt} / \mathrm{Ljpt}])$ & & $\begin{array}{l}1.481^{*} \\
(0.813)\end{array}$ & $\begin{array}{c}0.221^{* *} \\
(0.0939)\end{array}$ & $\begin{array}{c}0.256^{* *} \\
(0.109)\end{array}$ & $\begin{array}{c}0.260^{* * *} \\
(0.0734)\end{array}$ \\
\hline EHT. exp. lmed.([Kit/Lit]/[Kjpt/Ljpt]) & & $\begin{array}{l}1.425^{*} \\
(0.820)\end{array}$ & $\begin{array}{l}0.125^{*} \\
(0.0651)\end{array}$ & $\begin{array}{l}0.149^{*} \\
(0.0755)\end{array}$ & $\begin{array}{c}0.124^{* * *} \\
(0.0455)\end{array}$ \\
\hline EHT. exp. hmed.([Kit/Lit]/[Ljpt/Ljpt]) & & $\begin{array}{l}1.392^{*} \\
(0.814)\end{array}$ & $\begin{array}{l}0.0745 \\
(0.0607)\end{array}$ & $\begin{array}{l}0.0752 \\
(0.0647)\end{array}$ & $\begin{array}{l}0.0446 \\
(0.0639)\end{array}$ \\
\hline EHT. exp. high([Kit/Lit]/[Ljpt/Ljpt] $)$ & & $\begin{array}{l}1.325 \\
(0.824)\end{array}$ & & & \\
\hline EHT exp. & $\begin{array}{l}1.494^{*} \\
(0.788)\end{array}$ & & & & \\
\hline Constant & $\begin{array}{c}10.38^{* * *} \\
(3.233)\end{array}$ & $\begin{array}{c}10.59^{* * *} \\
(3.254)\end{array}$ & $\begin{array}{c}3.040^{* * *} \\
(0.404)\end{array}$ & $\begin{array}{c}2.840^{* * *} \\
(0.409)\end{array}$ & $\begin{array}{c}4.094^{* * *} \\
(0.0427)\end{array}$ \\
\hline Observations & 1113 & 1113 & 1113 & 1113 & 1113 \\
\hline$R^{2}$ & 0.973 & 0.973 & 0.975 & 0.975 & \\
\hline Province-Year FE & $\mathrm{NO}$ & $\mathrm{NO}$ & YES & $\mathrm{NO}$ & YES \\
\hline Industry-Year FE & YES & YES & YES & NO & YES \\
\hline Province-Ind. FE & NO & NO & YES & $\mathrm{NO}$ & YES \\
\hline Prov.-Ind.-Year FE & $\mathrm{NO}$ & $\mathrm{NO}$ & $\mathrm{NO}$ & YES & $\mathrm{NO}$ \\
\hline
\end{tabular}

ind.-prov. clustered standard errors in parentheses; (1)-(4): OLS estimation based on 2002 and 2006

(5): 2-step estimation; 1st step firm FE with private inputs based on 2000, 2001, 2002 and 2006 2nd step: based on 2002 and 2006 and coefficients of private inputs imposed 
Table 6: Robustness I

\begin{tabular}{|c|c|c|c|c|c|}
\hline VARIABLES & $\begin{array}{c}(1) \\
\text { sales }\end{array}$ & $\begin{array}{c}(2) \\
\text { sales }\end{array}$ & $\begin{array}{c}(3) \\
\text { sales }\end{array}$ & $\begin{array}{c}(4) \\
\text { sales }\end{array}$ & $\begin{array}{c}(5) \\
\text { sales }\end{array}$ \\
\hline capital & 0.0585 & $\begin{array}{c}0.0482^{* * *} \\
(0.0180)\end{array}$ & $\begin{array}{c}0.0755^{* * *} \\
(0.0120)\end{array}$ & $\begin{array}{c}0.0576^{* * *} \\
(0.0194)\end{array}$ & $\begin{array}{c}0.0474^{* * *} \\
(0.0180)\end{array}$ \\
\hline labour & 0.253 & $\begin{array}{c}0.258^{* * *} \\
(0.0190)\end{array}$ & $\begin{array}{c}0.244^{* * *} \\
(0.0282)\end{array}$ & $\begin{array}{c}0.232^{* * *} \\
(0.0251)\end{array}$ & $\begin{array}{c}0.259^{* * *} \\
(0.0191)\end{array}$ \\
\hline materials & 0.714 & $\begin{array}{c}0.719 * * * \\
(0.0301)\end{array}$ & $\begin{array}{c}0.720^{* * *} \\
(0.0198)\end{array}$ & $\begin{array}{c}0.718^{* * *} \\
(0.0195)\end{array}$ & $\begin{array}{c}0.719^{* * *} \\
(0.0303)\end{array}$ \\
\hline foreign & $0.0509^{* * *}$ & $\begin{array}{l}0.0308 \\
(0.0269)\end{array}$ & $\begin{array}{l}0.0280 \\
(0.0276)\end{array}$ & $\begin{array}{l}0.0295 \\
(0.0270)\end{array}$ & $\begin{array}{l}0.0302 \\
(0.0273)\end{array}$ \\
\hline large & -0.00309 & $\begin{array}{l}0.0311 \\
(0.0376)\end{array}$ & $\begin{array}{l}0.0277 \\
(0.0330)\end{array}$ & $\begin{array}{l}0.0238 \\
(0.0369)\end{array}$ & $\begin{array}{l}0.0313 \\
(0.0376)\end{array}$ \\
\hline exporter & 0.0392 & & $\begin{array}{l}0.0192 \\
(0.0241)\end{array}$ & $\begin{array}{l}0.0202 \\
(0.0248)\end{array}$ & $\begin{array}{l}0.0197 \\
(0.0243)\end{array}$ \\
\hline crime & $-0.0270 * * *$ & $\begin{array}{c}-0.0199 \\
(0.0154)\end{array}$ & $\begin{array}{r}-0.0207 \\
(0.0152)\end{array}$ & $\begin{array}{c}-0.0194 \\
(0.0149)\end{array}$ & $\begin{array}{r}-0.0201 \\
(0.0155)\end{array}$ \\
\hline EHT exp. low & $0.149^{* * *}$ & $\begin{array}{c}0.220^{* *} \\
(0.0939)\end{array}$ & $\begin{array}{c}-0.0845 \\
(0.126)\end{array}$ & $\begin{array}{l}0.198 \\
(0.138)\end{array}$ & $\begin{array}{c}0.227^{* *} \\
(0.0970)\end{array}$ \\
\hline EHT exp. lmed. & $0.0939^{* * *}$ & $\begin{array}{l}0.124^{*} \\
(0.0652)\end{array}$ & $\begin{array}{c}0.00714 \\
(0.0791)\end{array}$ & $\begin{array}{l}0.141 \\
(0.105)\end{array}$ & $\begin{array}{l}0.130^{*} \\
(0.0659)\end{array}$ \\
\hline EHT exp. hmed. & 0.0722 & $\begin{array}{l}0.0742 \\
(0.0606)\end{array}$ & $\begin{array}{l}0.0196 \\
(0.0576)\end{array}$ & $\begin{array}{l}0.0531 \\
(0.0698)\end{array}$ & $\begin{array}{l}0.0789 \\
(0.0544)\end{array}$ \\
\hline EHT exp. high & & & & & $\begin{array}{c}0.0141 \\
(0.0758)\end{array}$ \\
\hline EHT exp. [exporter] & & $\begin{array}{c}-0.0253 \\
(0.0325)\end{array}$ & & & \\
\hline Constant & $\begin{array}{c}2.859^{* * *} \\
(0.773)\end{array}$ & $\begin{array}{c}3.034^{* * *} \\
(0.404)\end{array}$ & $\begin{array}{c}2.016^{* * *} \\
(0.446)\end{array}$ & $\begin{array}{c}3.174^{* * *} \\
(0.423)\end{array}$ & $\begin{array}{c}3.041^{* * *} \\
(0.403)\end{array}$ \\
\hline Observations & 1,113 & 1,113 & 1,113 & 1,113 & 1,113 \\
\hline$R^{2}$ & 0.970 & 0.975 & 0.975 & 0.975 & 0.975 \\
\hline Province-Year FE & YES & YES & YES & YES & YES \\
\hline Industry-Year FE & $\mathrm{NO}$ & YES & YES & YES & YES \\
\hline Province-Ind. FE & $\mathrm{NO}$ & YES & YES & YES & YES \\
\hline Prov.-Ind.-Year FE & $\mathrm{NO}$ & $\mathrm{NO}$ & $\mathrm{NO}$ & NO & \\
\hline
\end{tabular}

ind.-prov. clustered standard errors in parentheses

OLS estimates based on 2002 and 2006.

(1): CGM Wildboot with clustering at prov. and ind. level

(2) share of EHT. exp. interacted with export status

(3) relative labor use interacted with share of EHT exp.

(4) relative capital use interacted with share of EHT exp.

(5) relative capital intensity categories based on 20th percentiles intervals 


\begin{tabular}{|c|c|c|c|c|c|}
\hline VARIABLES & $\begin{array}{c}(1) \\
\text { sales }\end{array}$ & $\begin{array}{c}(2) \\
\text { sales }\end{array}$ & $\begin{array}{c}(3) \\
\text { sales }\end{array}$ & $\begin{array}{c}(4) \\
\text { sales }\end{array}$ & $\begin{array}{c}(5) \\
\text { sales }\end{array}$ \\
\hline capital & $\begin{array}{c}-0.00379 \\
(0.0306)\end{array}$ & $\begin{array}{c}0.0510^{* * *} \\
(0.0296)\end{array}$ & $\begin{array}{c}0.0509^{* * *} \\
(0.0304)\end{array}$ & $\begin{array}{c}0.0494^{* * *} \\
(0.0192)\end{array}$ & $\begin{array}{c}0.0484^{* * *} \\
(0.0185)\end{array}$ \\
\hline labour & $\begin{array}{c}0.448^{* * *} \\
(0.0876)\end{array}$ & $\begin{array}{c}0.255^{* * *} \\
(0.0181)\end{array}$ & $\begin{array}{c}0.254^{* * *} \\
(0.0183)\end{array}$ & $\begin{array}{c}0.258^{* * *} \\
(0.0171)\end{array}$ & $\begin{array}{c}0.258^{* * *} \\
(0.0191)\end{array}$ \\
\hline materials & $\begin{array}{c}0.697^{* * *} \\
(0.0303)\end{array}$ & $\begin{array}{c}0.719^{* * *} \\
(0.0190)\end{array}$ & $\begin{array}{c}0.720^{* * *} \\
(0.0192)\end{array}$ & $\begin{array}{c}0.719 * * * \\
(0.0301)\end{array}$ & $\begin{array}{c}0.719^{* * *} \\
(0.0302)\end{array}$ \\
\hline foreign & $\begin{array}{c}-0.0355 \\
(0.102)\end{array}$ & $\begin{array}{c}0.0306 \\
(0.0268)\end{array}$ & $\begin{array}{l}0.0322 \\
(0.0268)\end{array}$ & $\begin{array}{l}0.0300 \\
(0.0268)\end{array}$ & $\begin{array}{l}0.0309 \\
(0.0269)\end{array}$ \\
\hline large & $\begin{array}{c}-0.0354 \\
(0.151)\end{array}$ & $\begin{array}{c}0.0306 \\
(0.0379)\end{array}$ & $\begin{array}{l}0.0328 \\
(0.0387)\end{array}$ & $\begin{array}{l}0.0301 \\
(0.0375)\end{array}$ & $\begin{array}{l}0.0290 \\
(0.0377)\end{array}$ \\
\hline exporter & $\begin{array}{l}-0.0515 \\
(0.0841)\end{array}$ & $\begin{array}{l}0.0197 \\
(0.0244)\end{array}$ & $\begin{array}{l}0.0192 \\
(0.0245)\end{array}$ & $\begin{array}{l}0.0199 \\
(0.0242)\end{array}$ & $\begin{array}{l}0.0201 \\
(0.0242)\end{array}$ \\
\hline crime & $\begin{array}{c}0.0223 \\
(0.0412)\end{array}$ & $\begin{array}{c}-0.0205 \\
(0.0154)\end{array}$ & $\begin{array}{r}-0.0197 \\
(0.0156)\end{array}$ & $\begin{array}{r}-0.0195 \\
(0.0154)\end{array}$ & $\begin{array}{c}-0.0203 \\
(0.0154)\end{array}$ \\
\hline EHT exp. low $([$ Kit/Lit $] /[$ Kjpt/Ljpt $])$ & $\begin{array}{c}0.450 * * * \\
(0.105)\end{array}$ & $\begin{array}{c}0.308^{*} \\
(0.155)\end{array}$ & $\begin{array}{l}0.369^{*} \\
(0.202)\end{array}$ & $\begin{array}{c}0.587^{* * *} \\
(0.219)\end{array}$ & $\begin{array}{c}0.0541^{* *} \\
(0.0244)\end{array}$ \\
\hline EHT exp. lmed.([Kit/Lit]/[Kjpt/Ljpt]) & $\begin{array}{c}0.303^{* * *} \\
(0.0788)\end{array}$ & $\begin{array}{l}0.175 \\
(0.107)\end{array}$ & $\begin{array}{l}0.223 \\
(0.141)\end{array}$ & $\begin{array}{c}0.326^{* *} \\
(0.159)\end{array}$ & $\begin{array}{c}0.0304^{*} \\
(0.0166)\end{array}$ \\
\hline EHT exp. hmed.([Kit/Lit]/[Ljpt/Ljpt]) & $\begin{array}{c}-0.0150 \\
(0.128)\end{array}$ & $\begin{array}{c}0.109 \\
(0.0991)\end{array}$ & $\begin{array}{c}0.123 \\
(0.126)\end{array}$ & $\begin{array}{l}0.179 \\
(0.148)\end{array}$ & $\begin{array}{c}0.0211 \\
(0.0160)\end{array}$ \\
\hline Constant & $\begin{array}{c}4.440 * * * \\
(0.950)\end{array}$ & $\begin{array}{c}3.021^{* * *} \\
(0.403)\end{array}$ & $\begin{array}{c}3.010^{* * *} \\
(0.383)\end{array}$ & $\begin{array}{c}3.048^{* * *} \\
(0.405)\end{array}$ & $\begin{array}{c}3.062^{* * *} \\
(0.402)\end{array}$ \\
\hline Observations & 1,113 & 1,113 & 1,095 & 1,113 & 1,113 \\
\hline $\begin{array}{l}R^{2} \\
\text { Number of eec_panelid }\end{array}$ & $\begin{array}{c}0.966 \\
981\end{array}$ & 0.975 & 0.975 & 0.975 & 0.975 \\
\hline Province-Year FE & YES & YES & YES & YES & YES \\
\hline Industry-Year FE & YES & YES & YES & YES & YES \\
\hline Province-Ind. FE & YES & YES & YES & YES & YES \\
\hline Firm FE & YES & $\mathrm{NO}$ & $\mathrm{NO}$ & $\mathrm{NO}$ & $\mathrm{NO}$ \\
\hline
\end{tabular}

${ }^{* * *} \mathrm{p}<0.01,{ }^{* *} \mathrm{p}<0.05,{ }^{*} \mathrm{p}<0.1$

ind.-prov. clustered standard errors in parentheses

OLS estimates based on 2002 and 2006

(1) Firm fixed effects added

(2) EHT exp. as a ratio of all exp. in these categories

(3) same as (2) except that emergency and public works is excluded from denominator

(4) broad definition of EHT expenditure used

(5) narrow definition of EHT expenditure used 
Table 8: Robustness III

\begin{tabular}{|c|c|c|c|}
\hline VARIABLES & $\begin{array}{c}(1) \\
\text { sales }\end{array}$ & $\begin{array}{c}(2) \\
\text { sales }\end{array}$ & $\begin{array}{c}(3) \\
\text { sales }\end{array}$ \\
\hline capital & $\begin{array}{c}0.0581^{* * *} \\
(0.0183)\end{array}$ & $\begin{array}{c}0.0519 * * * \\
(0.0183)\end{array}$ & $\begin{array}{c}0.0487^{* * *} \\
(0.0304)\end{array}$ \\
\hline labour & $\begin{array}{c}0.249^{* * *} \\
(0.0287)\end{array}$ & $\begin{array}{c}0.255^{* * *} \\
(0.0191)\end{array}$ & $\begin{array}{c}0.258^{* * *} \\
(0.0191)\end{array}$ \\
\hline materials & $\begin{array}{c}0.719 * * * \\
(0.0192)\end{array}$ & $\begin{array}{c}0.719^{* * *} \\
(0.0300)\end{array}$ & $\begin{array}{c}0.719 * * * \\
(0.0182)\end{array}$ \\
\hline foreign & $\begin{array}{l}0.0309 \\
(0.0270)\end{array}$ & $\begin{array}{l}0.0309 \\
(0.0270)\end{array}$ & $\begin{array}{l}0.0310 \\
(0.0270)\end{array}$ \\
\hline large & $\begin{array}{l}0.0253 \\
(0.0379)\end{array}$ & $\begin{array}{l}0.0279 \\
(0.0376)\end{array}$ & $\begin{array}{l}0.0280 \\
(0.0375)\end{array}$ \\
\hline exporter & $\begin{array}{l}0.0205 \\
(0.0244)\end{array}$ & $\begin{array}{c}0.0202 \\
(0.0243)\end{array}$ & $\begin{array}{l}0.0206 \\
(0.0243)\end{array}$ \\
\hline crime & $\begin{array}{c}-0.0205 \\
(0.0153)\end{array}$ & $\begin{array}{l}-0.0204 \\
(0.0154)\end{array}$ & $\begin{array}{l}-0.0204 \\
(0.0154)\end{array}$ \\
\hline EHT exp. low([Kit/Lit]/[Kjpt/Ljpt] $)$ & $\begin{array}{c}0.182 \\
(0.113)\end{array}$ & $\begin{array}{c}0.1000^{* *} \\
(0.0482)\end{array}$ & $\begin{array}{c}0.0530^{* *} \\
(0.0237)\end{array}$ \\
\hline EHT exp. lmed.([Kit/Lit]/[Kjpt/Ljpt] $)$ & $\begin{array}{l}0.0904 \\
(0.0747)\end{array}$ & $\begin{array}{c}0.0542^{*} \\
(0.0319)\end{array}$ & $\begin{array}{c}0.0284^{*} \\
(0.0159)\end{array}$ \\
\hline EHT exp. hmed.([Kit/Lit]/[Ljpt/Ljpt]) & $\begin{array}{c}0.100 \\
(0.0794)\end{array}$ & $\begin{array}{l}0.0406 \\
(0.0323)\end{array}$ & $\begin{array}{l}0.0204 \\
(0.0157)\end{array}$ \\
\hline Constant & $\begin{array}{c}3.030^{* * *} \\
(0.399)\end{array}$ & $\begin{array}{c}3.062^{* * *} \\
(0.404)\end{array}$ & $\begin{array}{c}3.076^{* * *} \\
(0.400)\end{array}$ \\
\hline Observations & 1,113 & 1,113 & 1,113 \\
\hline$R^{2}$ & 0.975 & 0.975 & 0.975 \\
\hline Province-Year FE & YES & YES & YES \\
\hline Industry-Year FE & YES & YES & YES \\
\hline Province-Ind. FE & YES & YES & YES \\
\hline
\end{tabular}

*** $\mathrm{p}<0.01,{ }^{* *} \mathrm{p}<0.05,{ }^{*} \mathrm{p}<0.1$

ind.-prov. clustered standard errors in parentheses

OLS estimation based on 2002 and 2006

(1) EHT spending only includes education exp. categories

(2) EHT spending only includes health exp. categories

(3) EHT spending only includes transport exp. categories 


\section{A Appendix}

\section{A.1 The System of Fiscal Decentralization in South Africa}

Since the end of the Apartheid era, South Africa has undergone wide-ranging fiscal reforms, and a system of transparent, constitutionally compliant intergovernmental fiscal relations has been created. Government now comprises three spheres: national, provincial and local. The fiscal system departs from conventional prescripts of fiscal federalism however because there is a mismatch between expenditure and revenue powers at each of these different levels of government (Ajam and Aron, 2007).

Public expenditure policy is decentralized in a range of important areas. Provincial governments are largely responsible for spending on provincial roads, education (except higher education), health services, public transportation, social welfare services, housing and agriculture. For these functions, the level of public spending by the national government is very low, and the national government is mainly responsible for setting minimum norms and standards and for monitoring the overall implementation by provincial governments. It also collects data on provincial public spending (Momoniat, 2002). The expenditure that the national government undertakes can be expected to leave firm productivity unaffected over the medium run, or it finances public goods such as national roads or higher education and research. In these cases, significant country-wide spillovers imply that there is no or little variation between the provinces. By contrast, provincial governments provide goods and services that are unlikely to entail significant spillovers across provinces.

At the same time, the revenue side of government in South Africa is fairly centralized: provincial governments collect very little revenue, and the income raised within the province typically amounts to less than 5 per cent of the provincial budget (Ajam and Aron, 2007). In the period that we consider, provinces have neither imposed nor collected broad base taxes, and the revenue collected came from various licences (notably motor vehicle licences), sales of goods, services and capital assets and various small base taxes (e.g. taxes on gambling and horse racing). In addition, while in principle, provincial governments are allowed to borrow to finance capital expenditure, in practice borrowing is quite limited. Provincial governments are therefore highly dependent on transfers from the national government. They receive conditional grants which they have to earmark for pre-specified purposes, 
such as health, infrastructure, housing and social development, and they receive non-earmarked grants (which are referred to as 'equitable share grants') (Ajam and Aron, 2007). The level of the latter that a given province receives depends on range of social and economic indicators.

\section{A.2 Industry-Level Descriptive Statistics}

This Appendix reports the number of firms in the sample by industry, province and year. In some industries and provinces, there are relatively few firms (Table 8). Our results remain robust when we exclude the industries and provinces with few observations (we do not report these results). 
Table 9: Distribution of firms by industry across provinces

\begin{tabular}{lcccc}
\hline industry & $\begin{array}{c}\text { no. of obs } \\
(\mathbf{2 0 0 2}-\mathbf{2 0 0 6})\end{array}$ & $\begin{array}{c}\text { \% of obs. } \\
\text { in KN }\end{array}$ & $\begin{array}{c}\text { \% of obs. } \\
\text { in GT }\end{array}$ & $\begin{array}{c}\text { \% of obs. } \\
\text { in WC }\end{array}$ \\
\hline Mining \& quarrying & 3 & $0.0 \%$ & $33.3 \%$ & $66.7 \%$ \\
Sale, Maintenance \& repair of vehicles & 2 & $0.0 \%$ & $50.0 \%$ & $50.0 \%$ \\
Manufacture of food \& bevarages & 154 & $5.2 \%$ & $68.2 \%$ & $18.2 \%$ \\
Manufacture of tobacco products & 1 & $0.0 \%$ & $100.0 \%$ & $0.0 \%$ \\
Manufacture of textiles & 21 & $19.0 \%$ & $38.1 \%$ & $33.3 \%$ \\
Manufacture of wearing apparel & 115 & $14.8 \%$ & $57.4 \%$ & $19.1 \%$ \\
Manufacture of luggage \& footwear & 20 & $15.0 \%$ & $70.0 \%$ & $5.0 \%$ \\
Manufacture of wood & 49 & $16.3 \%$ & $61.2 \%$ & $20.4 \%$ \\
Manufacture of paper & 26 & $19.2 \%$ & $65.4 \%$ & $11.5 \%$ \\
Publishing, printing \& reproduction & 47 & $14.9 \%$ & $46.8 \%$ & $38.3 \%$ \\
Manufacture of coke \& refined petroleum & 3 & $0.0 \%$ & $100.0 \%$ & $0.0 \%$ \\
Manufacture of chemicals & 122 & $8.2 \%$ & $69.7 \%$ & $14.8 \%$ \\
Manufacture of rubber \& plastics & 47 & $8.5 \%$ & $68.1 \%$ & $19.1 \%$ \\
Manufacture of non-metallic products & 25 & $12.0 \%$ & $68.0 \%$ & $20.0 \%$ \\
Manufacture of basic metals & 20 & $0.0 \%$ & $100.0 \%$ & $0.0 \%$ \\
Manufacture of metal products & 149 & $15.4 \%$ & $69.8 \%$ & $11.4 \%$ \\
Manufacture of machinery & 64 & $4.7 \%$ & $84.4 \%$ & $10.9 \%$ \\
Manufacture of office machinery & 2 & $0.0 \%$ & $100.0 \%$ & $0.0 \%$ \\
Manufacture of electrical machinery & 65 & $6.2 \%$ & $84.6 \%$ & $4.6 \%$ \\
Manufacture of motor vehicles & 24 & $12.5 \%$ & $62.5 \%$ & $4.2 \%$ \\
Manufacture of furniture & 150 & $6.7 \%$ & $65.3 \%$ & $22.0 \%$ \\
Recycling & 1 & $0.0 \%$ & $0.0 \%$ & $100.0 \%$ \\
Wholesale \& retail trade & 2 & $0.0 \%$ & $100.0 \%$ & $0.0 \%$ \\
Hotels \& restuarants & 1 & $0.0 \%$ & $100.0 \%$ & $0.0 \%$ \\
\hline all, 2002 - 2006 & $\mathbf{1 1 1 3}$ & $\mathbf{1 0 . 1 \%}$ & $\mathbf{6 7 . 7 \%}$ & $\mathbf{1 6 . 7 \%}$ \\
\hline Note: Eastern
\end{tabular}

Note: Eastern Cape is omitted and contains the remaining number of firms.

KN (Kwazulu-Natal), GT (Gauteng), WC (Western Cape) 


\section{A.3 Categorization of Public Expenditure}

In the empirical specifications, we assume that expenditure within education, health, as well as public infrastructure and transportation (EHT) is increased and that this increase is offset using expenditure outside these areas and other expenditure on specific items within these areas. The underlying assumption is that EHT expenditure affects productivity to a larger extent than the offsetting expenditure over a period of 1 to 2 years.

Within spending on public infrastructure and transportation referred to as 'transport expenditure', we assume that spending on public transport, traffic management and road infrastructure which includes spending on road maintenance can be expected to deliver fairly quickly tangible benefits for firms. For instance, improved traffic lights may cut travel time, filling potholes lowers the cost for repairs, and new bus lines help the work force to reach their workplace more quickly. Spending on public health may also rapidly improves labor productivity, if for instance it results in increased availability of drugs against common diseases, or if public awareness to prevent accidents or certain types of diseases increases. We therefore consider spending on district and provincial health services as productive. Here, we expect that public spending may ensure that the work force remains fit for work.

Even spending on education may have almost immediate effects on productivity: for instance, as a result of education spending on early childhood development, labor productivity of the parents may improve fairly quickly. In addition, improved education of students shortly prior to graduation or spending on short courses for adults may affect labor productivity over the medium run because this type of education is rather short and provides parts of the workforce with skills which are directly relevant for their jobs. We therefore expect that spending on further education and training as well as adult basic education and training as well as spending on public and private schools in general potentially affects private productivity over the medium run.

However, other subcategories are likely to hardly affect productivity of firms over the medium run, or not at all. For all three areas, we exclude spending on administration as there are only indirect effects, at best. For the same reason, within the health sector, we exclude health care support services and health facilities management. We also exclude spending on health sciences and training as any potential productive effects only materialize over longer time horizons, and we exclude central hospital services 
which are likely to treat many patients who are not part of the work force, at least temporarily. In addition, we exclude emergency medical services which includes emergency and planned patient transport; here the link to firm-level productivity is also less clear. With respect to education spending, apart from administration, we exclude spending on auxiliary and associated services and on public special school education where the links with private sector productivity are also less direct.

Finally, within the public infrastructure and transportation category, there are a number of areas which are probably less or not relevant at all for firm productivity. This includes public works which affects productivity at best over longer horizons or not at all (e.g., spending on public works in agriculture which we are unable to separate from spending on public works in say education) and spending on programmes within communities which can expected to have social rather than productive benefits.

Table 10 provides an overview of how we categorize public spending. Obviously, we recognize that one could also make alternative choices about which subcategories are considered as productive within the health, education and public infrastructure and transportation categories. We therefore consider the robustness of the our results to these choices in Section 5 .

\section{References}

[1] C. Adam and D. Bevan, "Fiscal deficits and growth in developing countries," Journal of Public Economics, vol. 89, no. 4, pp. 571-597, 2005.

[2] P. Agénor, "Fiscal policy and endogenous growth with public infrastructure," Oxford Economic Papers, vol. 60, no. 1, pp. 57-87, 2008a.

[3] — , "Health and infrastructure in a model of endogenous growth," Journal of Macroeconomics, vol. 30, no. 4, pp. 1407-1422, 2008b.

[4] T. Ajam and J. Aron, "Fiscal renaissance in a democratic South Africa," Journal of African Economies, vol. 16, no. 5, pp. 745-781, 2007.

[5] J. Arnold, A. Mattoo, and G. Narciso, "Services inputs and firm productivity in Sub-Saharan Africa: Evidence from firm-level data," Journal of African Economies, vol. 17, no. 4, pp. 578-599, 2008. 
Table 10: Fiscal variables provided by the South African Treasury

\begin{tabular}{ll}
\hline \hline Variable & Description (all in logs) \\
\hline total expenditure & total provincial expenditure / GDP \\
\hline EHT expenditure & $\begin{array}{l}\text { health expenditure, education } \\
\text { expenditure, transport \& } \\
\text { capital expenditure }\end{array}$ \\
\hline Education expenditure & $\begin{array}{l}\text { public ordinary school education, independent school subsidies, } \\
\text { further education and training, adult basic training, } \\
\text { early childhood development }\end{array}$ \\
\hline Health expenditure & district health services, provincial hospital services \\
\hline Transport \& capital exp. & road infrastructure, public transport, traffic management \\
\hline & $\begin{array}{l}\text { mainly agriculture, social development, housing, sport, } \\
\text { recreation, arts and culture, administration, } \\
\text { education (only public special school education, } \\
\text { auxiliary and associated services) } \\
\text { health (emergency medical services, central hospital services, } \\
\text { health sciences and training, health care support services, } \\
\text { health facilities management) } \\
\text { public infrastructure and transport (public works, } \\
\text { community-based programme) }\end{array}$ \\
\hline
\end{tabular}


[6] B. H. Baltagi and N. Pinnoi, "Public capital stock and state productivity growth: further evidence from an error components model," Empirical Economics, vol. 20, no. 2, pp. 351-359, 1995.

[7] R. Barro, "Government spending in a simple model of economic growth," Journal of Political Economy, vol. 98, no. 5, pp. 103-25, 1990.

[8] F. Bastos and J. Nasir, "Productivity and the Investment Climate: What Matters Most?" World Bank Policy Research Paper, no. 3335, 2004

[9] G. Bekes and B. Murakozy, "Firm Behaviour and Public Infrastructure: The Case of Hungary," KTI/IE Discussion Papers, no. 4, 2005.

[10] A. Cameron, J. Gelbach, and D. Miller, "Bootstrap-based improvements for inference with clustered errors," The Review of Economics and Statistics, vol. 90, no. 3, pp. 414-427, 2008.

[11] S. Datta, "The impact of improved highways on indian firms," Journal of Development Economics, vol. 99, no. 1, pp. 46-57, 2012.

[12] P. David and T. Van de Klundert, "Biased efficiency growth and capitallabor substitution in the U.S., 1899-1960," The American Economic Review, pp. 357-394, 1965.

[13] S. Devarajan, V. Swaroop, and H.-f. Zou, "The composition of public expenditure and economic growth," Journal of Monetary Economics, vol. 37, no. 2, pp. 313-344, 1996.

[14] D. Dollar, M. Hallward-Driemeier, and T. Mengistae, "Investment Climate and Firm Performance in Developing Economies," Economic Development and Cultural Change, vol. 54, no. 1, pp. 1-31, 2005.

[15] P. Evans and G. Karras, "Are government activities productive? evidence from a panel of us states," The Review of economics and statistics, pp. 1-11, 1994.

[16] T. Gabe, "Local fiscal policy and establishment growth," Journal of Regional Analysis and Policy, vol. 33, no. 1, pp. 57-80, 2003.

[17] T. Garcia-Milà and T. J. McGuire, "The contribution of publicly provided inputs to states' economies," Regional Science and Urban Economics, vol. 22, no. 2, pp. 229-241, 1992. 
[18] N. Gemmell, F. Misch, and B. Moreno-Dodson, "Public spending and long-run growth in practice: Concepts, tools, and evidence," Is Fiscal Policy the Answer?: A Developing Country Perspective, p. 69, 2012.

[19] H. Hong and S. Ahmed, "Government spending on public goods: Evidence on growth and poverty," Economic 85 Political Weekly, vol. 44, no. 31, pp. 103-108, 2009.

[20] R. Kneller, M. Bleaney, and N. Gemmell, "Fiscal policy and growth: evidence from oecd countries," Journal of Public Economics, vol. 74, no. 2, pp. 171-190, 1999.

[21] J. Levinsohn and A. Petrin, "Estimating production functions using inputs to control for unobservables," Review of economic studies, vol. 70, no. 2, pp. 317-341, 2003.

[22] J. E. Ligthart and R. M. M. Suárez, "The productivity of public capital: A meta-analysis," in Infrastructure Productivity Evaluation. Springer, 2011, pp. 5-32.

[23] R. López and S. Miller, "The Structure of Public Expenditure: A Robust Predictor of Economic Development?" Unpublished manuscript, 2007.

[24] K. Mera, "Ii. regional production functions and social overhead capital: An analysis of the japanese case," Regional and Urban Economics, vol. 3, no. 2, pp. 157-185, 1973.

[25] I. Momoniat, "Fiscal Decentralisation in South Africa: a Practitioner's Perspective," in Managing Fiscal Decentralization, E. Ahmad and V. Tanzi, Eds. Routledge, 2002, pp. 350-374.

[26] R. Reinikka and J. Svensson, "Coping with poor public capital," Journal of Development Economics, vol. 69, no. 1, pp. 51-70, 2002.

[27] D. Rodrik, "The debate over globalization: how to move forward by looking backward," Launching new global trade talks: an action agenda, p. 25, 1998.

[28] W. Romp and J. de Haan, "Public capital and economic growth: A critical survey," Perspektiven der Wirtschaftspolitik, vol. 8, no. S1, pp. 6-52, 042007. 
[29] C. Schwellnus and J. Arnold, "Do Corporate Taxes Reduce Productivity and Investment at the Firm Level? Cross-country Evidence from the Amadeus Dataset," OECD Economics Department Working Papers, no. 641, 2008.

[30] C. Shirley and C. Winston, "Firm inventory behavior and the returns from highway infrastructure investments," Journal of Urban Economics, vol. 55, no. 2, pp. 398-415, 2004.

[31] S. Straub, "Infrastructure and Growth in Developing Countries: Recent Advances and Research Challenges," World Bank Policy Research Paper, no. 4460, 2008. 